BULLETIN Bulletin hispanique

HISPANIQUE Université Michel de Montaigne Bordeaux

116-1 | 2014

Varia

\title{
Coincidencias y divergencias del arte narrativo de Max Aub con el existencialismo
}

el personaje existencial en Campo de sangre

\section{Manuel J. Villalba}

\section{OpenEdition}

\section{Journals}

Edición electrónica

URL: http://journals.openedition.org/bulletinhispanique/3034

DOI: 10.4000/bulletinhispanique.3034

ISSN: $1775-3821$

Editor

Presses universitaires de Bordeaux

Edición impresa

Fecha de publicación: 1 junio 2014

Paginación: 381-399

ISBN: 978-2-86781-931-5

ISSN: 0007-4640

\section{Referencia electrónica}

Manuel J. Villalba, « Coincidencias y divergencias del arte narrativo de Max Aub con el existencialismo », Bulletin hispanique [En línea], 116-1 | 2014, Publicado el 01 junio 2017, consultado el 23 mayo 2020 URL : http://journals.openedition.org/bulletinhispanique/3034; DOI : https://doi.org/10.4000/ bulletinhispanique.3034 


\title{
Coincidencias y divergencias del arte narrativo de Max Aub con el existencialismo: el personaje existencial en Campo de sangre
}

\author{
Manuel J. Villalba \\ Tennessee Technological University
}

Sans être un auteur existentialiste, Max Aub offre dans Campo de sangre une réflexion sur le problème de l'existence humaine posé par les après-guerres espagnole et européenne. Affirmant dans ce texte la dialectique sujet-monde, absente du roman existentialiste espagnol, la fiction aubienne accède à un objectivisme majeur dans la perception de la réalité et permet à Aub de garder foi en l'être humain et en l'utopie d'un monde plus juste.

Mots-clés: exil, dialectique, existentialisme, utopie.

Sin ser un autor existencialista, en Campo de sangre Max Aub reflexiona sobre el problema de la existencia humana planteado por las postguerras española y europea. Su afirmación de la dialéctica sujeto-mundo en este texto, ausente en la novela existencial española, condujo la novelística aubiana a un mayor objetivismo en la percepción de la realidad. Con ello Aub consiguió mantener viva su fe en el ser humano y la utopia de un mundo más justo.

Palabras claves : exilio, dialéctica, existencialismo, utopia.

Even though he was not an existential author, Max Aub discusses in Campo de Sangre the problem of the human existence posed by the Spanish and European post-war. In this text, the affirmation of the subject-world dialectics, missing in the Spanish existential novel, leads the Aubian fiction to a major objectivism in its perception of reality. This allowed Aub to keep faith in human beings and in the utopia of a juster world.

Keywords : exile, dialectic, existentialism, utopia. 
$\mathrm{M}$ ax Aub siempre rechazó el calificativo "existencialista» o la influencia existencialista en su obra, y criticó las bases del existencialismo filosófico y literario. Sin embargo, estas afirmaciones necesitan ser matizadas. Por un lado, a lo largo de sus diarios y artículos de crítica literaria podemos comprobar cómo la opinión de Aub sobre el existencialismo fue evolucionando con los años hasta llegar a aceptar la conexión con sus planteamientos; y, por otro lado, en las novelas de El laberinto mágico es posible así mismo rastrear similitudes y diferencias con la novela existencial en lo relativo al desarrollo del personaje y la construcción del sujeto. En concreto, el análisis de este trabajo se va a centrar en Campo de sangre ${ }^{1}$, la novela del ciclo donde la conexión con el existencialismo es más evidente.

\section{MaX aub y el existencialismo}

Las primeras referencias al existencialismo en los diarios de Aub datan de finales de los años 40. Dos parecen ser los aspectos del existencialismo con los que Aub está en desacuerdo por esos años. Por un lado, su raíz irracionalista y, por otro, su percepción de la obra de arte. En primer lugar, el 7 de julio de 1956 Aub señala cómo el existencialismo se basa en el mismo principio irracional que el Romanticismo ${ }^{2}$. Para Aub el existencialismo nació como reacción contra la razón, de la misma manera que el Romanticismo fue una reacción contra las «luces» de la Ilustración. El 11 de octubre de 1958 Aub amplía esta idea y afirma la raíz común de la fenomenología, el existencialismo y el fascismo ${ }^{3}$. La reducción del mundo y la autonomía del sujeto, ideas básicas de la fenomenología y que están en la base de la filosofía de Martín Heidegger, fueron las bases ideológicas del fascismo. La autonomía subjetiva tiene su paralelo en el hermetismo de la obra de arte, que Aub también achaca al movimiento el 7 de junio de $1950^{4}$. Aub se da cuenta en época muy temprana de la interconexión que existió entre el sujeto de la fenomenología con el hermetismo artístico de la vanguardia y la apropiación fascista del «superhombre». En su opinión, esta interconexión podía extenderse al existencialismo por su raíz irracionalista y subjetivista ${ }^{5}$.

Por otro lado, en 1948 apareció en la revista Cuadernos americanos el artículo de De Torre titulado El existencialismo en la literatura ${ }^{6}$, en el que señala Campo

1. Max Aub, Campo de sangre. Obras completas. El laberinto mágico II, vol. 3-A, ed. Luis Llorens Marzo, Valencia, Biblioteca Valenciana, Generalitat Valenciana, 2001.

2. Max Aub, Diarios, vol. II, ed. Manuel Aznar Soler, México D.F., Conaculta, 2000, p. 101.

3. M. Aub, Diarios II, ob. cit., p. 143.

4. Max Aub, Diarios, vol. I, ed. Manuel Aznar Soler, México D.F., Conaculta, 2000, p. 170.

5. Es interesante esta conexión entre el existencialismo y el arte de vanguardias. En esta opinión Max Aub coincide con Guillermo de Torre quien en Historia de las literaturas de vanguardias, Madrid, Guadarrama, 1965, le dedica un capítulo al existencialismo. Tres años más tarde este mismo autor reincide en esta idea en otro de sus libros: Ultraísmo, existencialismo y objetivismo, Madrid, Guadarrama, 1968.

6. Guillermo de Torre, «El existencialismo en la literatura», Cuadernos americanos, $\mathrm{n}^{\circ}$ 37.1, 1948, 253-272; \& no 38.2, 1948, 223-234. 
cerrado y Campo de sangre como ejemplos de novelas existencialistas españolas escritas en el exilio. Aub se sintió en la necesidad de contestar un ańo más tarde a De Torre en la misma revista a través de una carta abierta, dirigida a Roy Temple House, que previamente le había dirigido otra en la que coincidía con De Torre. Aquí Aub rechaza toda filiación o influencia del existencialismo, y declara su proximidad a otros autores como Hemingway, Malraux o Faulkner ${ }^{7}$. Aub explicita así cuál es su canon, que como podemos apreciar se aleja de los planteamientos existenciales.

Sin embargo, de la lectura de los diarios se deduce también la atracción que la obra de Albert Camus ejerció sobre Aub. Precisamente con Camus anota una larga conversación el 13 de octubre de 1958 acontecida en Francia con motivo de uno de los viajes de Aub al país galo ${ }^{8}$. La valoración del existencialismo fue matizándose en sus últimos años precisamente de la mano de Camus. El 11 de junio de 1967, Aub reconoce la influencia de la obra de Camus y de su concepto de justicia ${ }^{9}$. Sin duda, había algo que unía estrechamente a Camus y a Aub, más allá de las discrepancias artísticas y filosóficas: la idea de fraternidad, clave para entender la literatura y la postura intelectual del Aub exiliado ${ }^{10}$; y clave también en la obra de Camus, para quien el absurdo de la existencia humana es irresoluble, pero aúna fraternalmente a todos los seres humanos ante su común destino absurdo.

Soldevila Durante en su Obra narrativa de Max Aub (1929-1969) ${ }^{11}$ ahonda en esta relación y contradice al propio autor al clasificarle como escritor existencial. Señala Soldevila que desde el siglo XIX y a lo largo del siglo XX se produjo un acercamiento de la filosofía a la literatura, al que contribuyeron principalmente los autores existencialistas. Dentro de esta línea Albert Camus creó un nuevo tipo de escritor que Soldevila denomina existencialista práctico, y que destaca por una «especial preocupación por las relaciones entre las ideas y la conducta» y por no llevar su especulación a la sistematización filosófica. Afirma Soldevila que:

A este tipo de escritor nos complace asimilar a Max Aub, cuyo preciso conocimiento de la especulación existencialista contemporánea sólo tiene parejo en su arte para vivificarla en la problemática del grupo quizás más importante de sus personajes de ficción, y con los cuales no nos parece aventurada la hipótesis de una comunión sentimental por parte de su creador ${ }^{12}$.

7. Max Aub, «Una carta», Cuadernos americanos, no 44.2, 1949, p. 55.

8. La nota de Aub sobre el encuentro con Camus, Diarios II, p. 143, reza:

"Larga conversación con Camus, en la embajada. Teatro, Dostoievsky, nada. Quedamos en volver a vernos y «hablar en serio". Lo dudo. No sabe lo que quiere. Argelia en el pecho.»

9. Max Aub, Diarios, vol. III, ed. Manuel Aznar Soler, México D.F., Conaculta, p. 83.

10. La cultura, primero, del Frente Popular y, después, del exilio reactualizó muchos valores venidos del republicanismo francés del siglo XIX. Por ejemplo, Faber en su libro Exile and Cultural Hegemony. Spanish Intellectuals in Mexico, 1939-1975, Nashville, Vanderbilt U.P., 2002, p. 65, señala el origen decimonónico del concepto de «pueblo» que dominó en el imaginario republicano y exiliado.

11. Ignacio Soldevila Durante, La obra narrativa de Max Aub (1929-1969), Madrid, Gredos, 1973.

12. Soldevila, ob. cit., p. 191. 
En general, la especulación existencialista de Aub se percibe especialmente en la construcción del sujeto a partir de su experiencia como exiliado. Tanto Max Aub como sus personajes debieron plantearse las cuestiones fundamentales de su existencia ${ }^{13}$. Como vemos, el hecho de que Aub construya a sus personajes a partir de la autoconciencia de su propia subjetividad, su relación con el tiempo y su lugar en el grupo social permite a Soldevila contradecir la afirmación del propio escritor y afirmar su filiación existencialista. En lo que sí coinciden tanto el escritor como su crítico es en señalar las fuertes similitudes y coincidencias con la obra de Albert Camus.

\section{Paulino cuartero y el problema de la existencia}

La acción de Campo de sangre comienza el 31 de diciembre de 1937. Ese día el ejército rebelde llegaba a los alrededores de la ciudad de Teruel. Comenzaba así la contraofensiva rebelde sobre esta ciudad aragonesa, una de las más cruentas batallas de la Guerra Civil ${ }^{14}$. La primera parte de Campo de sangre transcurre a lo largo del día y de la Nochevieja de 1937. La batalla de Teruel y los bombardeos sobre Barcelona le sirven a Max Aub como punto de partida para explorar las consecuencias morales de la experiencia de la guerra.

La guerra es en Campo de sangre la «situación límite» que, en general en la novela existencial, provoca en el héroe la toma de conciencia de su propia existencia. Fue Karl Jaspers quien primero teorizó sobre la relación de la «situación límite» en la que está inmerso el sujeto con la toma de conciencia de su propia existencia. Para este filósofo existencialista:

Der Ursprung in den Grenzsituationen bringt den Grundantrieb, im Scheitern den Weg zum Sein zu gewinnen... In den Grenzsituationen zeigt sich entweder das Nichts, oder es wird fühlbar, was trotz und über allem verschwindenden Weltsein eigentlich ist ${ }^{15}$.

Roberts se hace eco de este concepto de Jaspers en su exégesis de la novela existencial. En la situación límite «es preciso que el hombre se reconozca a sí mismo en la situación, y que la misma se manifieste como una de sus posibilidades de ser» ${ }^{16}$. Este tipo de situación permite al sujeto separarse del mundo y oponerse a él. Este proceso de individualización le conduce a tomar conciencia de su existir. La angustia existencial es el precio que el sujeto debe pagar por su nuevo estado:

13. Campo de sangre, pp. 202 et 218.

14. La batalla de Teruel se desarrolló entre el 15 de diciembre de 1937 y el 19 de marzo de 1938.

15. Karl Jaspers, Einführung in die Philosophie, München, Piper, 1971, p. 20. «El origen de la "situación límite" incluye el principio impulsor, en cuyo fracaso permite alcanzar el camino del ser... En la "situación límite" se descubre, o se hace perceptible, la nada que es en verdad "a pesar de" y "por encima de" todo el mundo en desaparición.» [Mi traducción]

16. Gemma Roberts, Temas existenciales en la novela española de postguerra, Madrid, Gredos, 1978, p. 113. 
La angustia, en cambio, surge de la condición misma de la existencia humana como ser finito y limitado; es la expresión de la revelación del sujeto existente como libertad, como posibilidad, es decir, como algo que no es nada todavía ${ }^{17}$.

Uno de los elementos fundamentales del sujeto existencial es la libertad. La situación límite impone la necesidad de elegir una postura ante la propia existencia. Si la angustia es la primera consecuencia del despertar a la existencia del sujeto, la segunda es la obligación de tomar una decisión ética sobre la misma.

Así, en Campo de sangre la experiencia de la guerra permite a los personajes descubrir de su propia existencia. Los anti-héroes que deambulan por la novela intentan dar respuesta a la pregunta sobre el sentido de sus vidas y buscan una salida a la angustia que les aqueja. Además, la contienda bélica va a forzarles a adoptar una postura moral que les permita vivir a pesar de las contradicciones. Con el objetivo de explorar diferentes puntos de vista a estos interrogantes, Max Aub desarrolla sus personajes como representantes de diferentes planteamientos y contradicciones vitales ante la existencia. Varios son los personajes en los que es perceptible la huella del existencialismo. En este análisis nos vamos a centrar en Paulino Cuartero, probablemente el más rico y complejo de todos ellos.

Esa Nochevieja de 1937 varios amigos se dan cita para cenar. En una taberna de Barcelona han quedado, además del mismo Paulino Cuartero, Julián Templado y José Rivadavia, dos personajes que también aparecen en Campo $a^{a b i e r t{ }^{18}}$. A ellos se unen también: Santiago Ferro, al que todos conocen como Sancho y del que sabemos que es republicano por interés, y Jesús Herrera, de origen humilde y hecho a sí mismo en las calles de Madrid, autodidacta y socialista durante la República, ahora en la guerra ha abrazado el comunismo. Herrera es oficial del ejército republicano y acaba de llegar de permiso a Barcelona desde el frente de Teruel. Precisamente, la batalla de Teruel está en la mente de todos los comensales.

Durante la cena se produce un largo diálogo sobre el que sobrevuela el tema de la existencia. El diálogo sirve para confrontar diferentes puntos de vista ideológicos y nos permite conocer los planteamientos vitales de Paulino Cuartero. Los demás comensales le echan en cara su fe cristiana, la cual les sirve como escusa para poner en entredicho todas sus opiniones. Sin embargo, Cuartero nunca se amilana, ni se deja callar. De hecho, tiene su propia lectura de la guerra a partir de la defensa de los valores cristianos. Durante el paseo posterior a la cena, Cuartero expone su teoría «erasmista» de la guerra. El cristianismo honesto, basado en la fe y a la vez en la acción, está en el lado de la República. Al otro lado están los que dicen defender la fe católica y han proclamado que su lucha es una nueva cruzada, cuando en realidad, afirma Cuartero, su cristianismo no es más que hipocresía ritualista. La Guerra Civil, para este personaje, es una lucha de inspiración erasmista por un cristianismo más auténtico y sincero.

17. Roberts, ob. cit., p. 15.

18. Max Aub, Campo abierto. Obras completas. El laberinto mágico I, Vol. 2, ed. José Antonio Pérez Bowie, Valencia, Biblioteca Valenciana, Generalitat Valenciana, 2001. 
A través del personaje de Cuartero, Aub critica la idea de un cristianismo basado en la creencia oscurantista en un dios medieval, injusto y arbitrario, y en la percepción de este mundo como un valle de lágrimas. En opinión de Cuartero el auténtico cristianismo es el de la luz y la sinceridad del sentimiento religioso, y de la pureza de las enseńanzas de Jesucristo. Sólo apartando la hipocresía y el ritualismo es posible dar una respuesta cristiana a los problemas existenciales que plantea la guerra. El crítico Óscar Barrero Pérez nos recuerda como una de las características del héroe existencial es precisamente su aspiración a «acceder a un estrato de plenitud vital más auténtica» ${ }^{19}$. La búsqueda de la autenticidad y la denuncia de la hipocresía alentarán a Cuartero en su periplo vital a lo largo de toda la novela. En este personaje se interconectarán cristianismo, autenticidad y, como veremos más adelante, culpa. Esta interconexión no es en absoluto extraña a la literatura existencial. Gemma Roberts afirma que:

Para el pensamiento existencialista la «autenticidad» del existente supone un verdadero proceso de apropiación de la culpa original del hombre, algo muy semejante a la conversión religiosa, que implica el arrepentimiento y el nacimiento del «hombre nuevo $»^{20}$.

Precisamente, hacia el arrepentimiento es hacia donde se encamina la historia personal de Cuartero al final de la novela.

Acaba la conversación y todos los invitados a la cena se despiden después de su paseo por las calles de Barcelona. El narrador vuelve a ahondar en la postura vital de Paulino Cuartero describiendo su circunstancia cotidiana. Pilar Núñez, su mujer, es una mujer amargada, frustrada y cansada de atender y cuidar a sus cinco hijos. Nunca pierde la oportunidad para humillar y herir a su marido frente a sus hijos quienes ya han perdido todo respeto por su padre. Cuartero aguanta todos los reproches con paciencia y mansedumbre, y los justifica por las circunstancias tan duras que la guerra impone a la familia. A pesar de todo, Pilar le recrimina una y otra vez, por un lado, su incapacidad para salvaguardar el futuro material de la familia, y, por otro, culpa a su activismo político de las penurias que sufren. La ruptura afectiva del matrimonio cristaliza en el cese del contacto sexual. Pilar, una mujer reprimida sexualmente por la religiosidad católica, odia a su marido por haberla hecho caer en el pecado de la carne en múltiples ocasiones y le hace mendigar sus favores sexuales hasta que consigue que cese por completo en sus requerimientos. El infierno en que se ha convertido su vida familiar, se suma a la frustración de su vocación dramática. Cuartero, al igual que Max Aub, es autor de obras de teatro que nunca han llegado a ser estrenadas. Su mujer se lo recuerda frecuentemente y le compara con otros autores, como Marquina o Arniches, que a pesar de la guerra son capaces de estrenar sus obras en América.

El problema principal de Paulino Cuartero es la falta de fe en sí mismo para defender sus ideas y su obra, especialmente frente a su mujer, quien a lo

19. Óscar Barrero Pérez, La novela existencial española de posguerra, Madrid, Gredos, 1987, p. 81.

20. Roberts, ob. cit., p. 110. 
largo de los años de matrimonio ha ido minando su autoestima. A pesar de esta aparente pusilanimidad, encontramos elementos muy interesantes en su actitud vital. En primer lugar, Cuartero, antimilitarista y católico, es un tipo peculiar dentro de las filas republicanas. Pese a los reproches de su mujer, no cree posible haberse inhibido de la realidad circundante o haber adoptado una postura más egoísta. Su moral católica encierra necesariamente una toma de postura política. Para Cuartero «vivir es ya una política». Desde el comienzo de la guerra, ha trabajado para la Junta de Protección y Conservación del Tesoro Artístico. En Campo abierto estaba encargado de la evacuación de los fondos del Museo del Prado; ahora en Campo de sangre una de sus principales ocupaciones es la de convencer a los milicianos, principalmente anarquistas, de que no quemen las iglesias. Para Cuartero lo importante no es «la calidad de los objetos lo que valía, sino la de los hombres que los salvaban, su fe, su ansia de saber, su seguridad de servir ${ }^{21}$. Como vemos, su cristianismo tiene como principal objeto el bien del ser humano y no el dogma o el ritual.

En segundo lugar, esta visión humanista del cristianismo tiene para Cuartero una puesta en práctica de raigambre estoica. El narrador, cuando valora la reacción que el personaje muestra ante los reproches de su mujer, extrapola su respuesta a la vida en general:

Cuartero acepta este continuo martillear acedo. No intenta buscar otra salida. No entra para nada en su determinación el sentido del deber, ni la pusilanimidad, ni la vanagloria de toda desdicha. Acepta el mundo tal como es y se lo dan: por entereza viril ${ }^{22}$.

Tal vez sea esta actitud, la entereza viril, una forma de la templanza que preconizaban Marco Aurelio o Séneca en sus escritos. Cuartero tiene una visión determinista, casi fatalista, del mundo que acepta tal y como es. Todo lo que ocurre, ocurre por necesidad. Conoce los límites de su agencia. En primer lugar, lucha por cambiar la sociedad en lo que está dentro de sus posibilidades. De ahí nace su compromiso y su posicionamiento políticos. Y, en segundo lugar, procura permanecer impasible ante los acontecimientos que se escapan a sus posibilidades y que acepta con templanza y «entereza viril».

Más adelante, después de definir la moral práctica de Cuartero, el narrador nos permite conocer y perfilar sus ideas metafísicas y trascendentes. Se trata del capítulo: «Nacimiento de una comedia» construido sobre la misma idea que el texto de Miguel de Unamuno: Cómo se hace una novela ${ }^{23}$. Como en el libro de

21. Campo de sangre, ob. cit., p. 166.

22. Campo de sangre, ob. cit., p. 167.

23. Miguel de Unamuno, Cómo se hace una novela, Buenos Aires, Editorial Alba, 1927. Queda por hacerse un estudio detallado de la influencia de Miguel de Unamuno en la obra de Max Aub. Óscar Barrero Pérez, ob. cit., 41, considera que la novela existencialista de postguerra buscó en el 98 una tradición en la que enraizarse. Mientras que los escritores del interior buscaron en Baroja un antecedente, los del exilio lo hicieron en Unamuno. En esta línea se expresa Marra-López en Narrativa española fuera de España (1939-1961), Madrid, Guadarrama, 1963, pp. 71-8. Tres fueron las razones por las que el exilio buscó en Unamuno un guía filosófico y poético: en primer lugar, por su visión agónica del mundo permanentemente en lucha; en segundo lugar, por su 
Unamuno, este capítulo narra el proceso de creación de una obra literaria, en este caso una comedia. La voz del narrador deja paso al flujo de conciencia de Cuartero en el momento en que está creando su teatro. La obra naciente refleja un argumento muy del gusto del teatro de Unamuno, autor al que se remite y se cita continuamente ${ }^{24}$. El personaje principal de la obra decide publicar en el periódico La Vanguardia su propia esquela para que los milicianos dejen de hostigarle con interrogatorios y chantajes. Este hecho provoca equívocos que permiten a Cuartero reflexionar sobre la identidad del sujeto y la paradoja de los conceptos trascendentes. Para Cuartero, la esencia del teatro reside en la circunstancia de que no existen barreras definidas entre la vida y el arte: «En la vida se habla como en el teatro, o en el teatro se habla como en la vida? ${ }^{25}$, se pregunta Cuartero. Esta paradoja tiene una consecuencia transcendental, igual que en el teatro unamuniano. De hecho, el mismo Cuartero se encarga de establecer la conexión con la obra del rector salmantino al afirmar: «El solo hecho de la existencia del teatro, drama de Unamuno» ${ }^{26}$. Al igual que éste, Cuartero piensa que la creación de un personaje por su autor es paralela a la creación del hombre por Dios y que, si las barreras entre arte y vida no están claras, se abre la posibilidad a que el autor sea una creación del personaje, y Dios, una creación del ser humano. Afirma Cuartero: «Creo en el teatro, teatro. El teatro, prueba más evidente, la más única, de la falsedad del materialismo. El teatro, prueba de la existencia de Dios ${ }^{27}$. En esta visión espiritualista del teatro, el mismo texto es una demostración de la existencia de Dios:

Lo eterno es el espíritu. Espíritu igual a la lengua, igual a la literatura. Lo eterno: la literatura. Teatro: lengua y bulto; carne y espíritu; sangre y literatura. Del teatro, la lengua. La lengua, el texto. Lo que queda es la literatura; lo que se salva. Y yo quiero salvarme $e^{28}$.

Como vemos en la literatura se contiene una esperanza de salvación, de eternidad, de transcender a la propia limitación humana. El autor sobrevive en el texto como huella de su espíritu, de la misma manera que sabemos de la existencia de Dios, porque el ser humano y el mundo son las huellas dejadas por él mismo.

postura eminentemente moral, y, en tercer lugar, por su coincidencia en percibir el mundo como estático y su afán por atesorar el pasado, olvidándose del presente. Nos interesa señalar ahora la segunda. Unamuno hizo de su destierro una cuestión moral. Marra-López señala que, como a Unamuno, lo que impidió volver a los intelectuales del exilio fue un imperativo moral. Este aspecto moral está presente en toda la obra de Aub y en concreto en Campo de sangre.

24. Soldevila, ob. cit., p. 214, habla en su estudio de la influencia de Unamuno en la figura del escritor que aparece en El laberinto mágico. Afirma este crítico que: «Todos los artistas, todos los escritores que circulan por el mundo novelesco de Max Aub corren tras la obra que les dará esa supervivencia que buscan, unamunos que no pueden acabar de esperar en una trascendencia de orden teológico".

25. Campo de sangre, ob. cit., p. 197.

26. Campo de sangre, ob. cit., p. 195.

27. Campo de sangre, ob. cit., p. 197.

28. Campo de sangre, ob. cit., p. 199. 
La meta-ficción trascendental de influencia unamuniana es una diferencia importante con respecto a la novela existencial española. Señala Barrero que la meta-ficción y la reflexividad textual son elementos importantes de la novela existencial, pero, lejos de tener un valor trascendente en la reflexión de la existencia, configuran una herramienta de indagación del propio "yo $»^{29}$. En concreto, este crítico nos habla de la forma auto-biográfica confesional, abundante entre las novelas existenciales españolas, pero que queda lejos de la estética aubiana.

El análisis de la meta-ficción trascendental de este capítulo nos permite terminar de perfilar la posición existencial de Cuartero. El cristianismo de Cuartero se define, como hemos visto, por su búsqueda de una religiosidad auténtica, por una práctica moral estoica a la vez que comprometida y por una teología basada en la reflexividad de sus argumentos y una visión espiritual del texto literario. Bajo todo este edificio moral, subyace un grito de angustia existencial, de clara raigambre unamuniana, consecuencia de la experiencia inmediata de la guerra.

Después de este análisis, se observa cómo, en esta primera parte de Campo de sangre, Max Aub plantea diferentes temas y motivos que coinciden con los de la novela existencial: el problema de la existencia, el absurdo de la muerte, la angustia existencial, el personaje inmerso en una «situación límite», la búsqueda de la autenticidad. A todo ello se añade la influencia de Unamuno propia de la novela del exilio. Max Aub tiene especial interés en construir sus personajes principales sobre la postura moral que deben adoptar ante el mundo, ante el otro y ante sí mismos. De entre esos personajes destaca Paulino Cuartero, estoico creyente que busca un cristianismo más auténtico que responda a sus dudas y al que le queda por recorrer el difícil camino que la circunstancia de la guerra le ha preparado.

\section{LOS CAMIMOS DEL HÉROE EXISTENCIAL: PAULINO CUARTERO Y LA SOLEDAD}

Tras la segunda parte en la que se narra la toma de Teruel y la evacuación de civiles a Valencia, la tercera parte de Campo de sangre retoma la acción el 12 de febrero de 1938. Para esa fecha las tropas rebeldes se encontraban en plena contraofensiva sobre Teruel. El día 17 de enero había comenzado el movimiento de tropas y el 7 de febrero había tenido lugar el primer ataque nacional sobre el norte de la ciudad. Sin embargo, la acción de la novela, tras un intermedio localizado en Teruel, vuelve a la Barcelona asediada por los bombardeos enemigos. A lo largo de los capítulos finales se van desarrollando y definiendo las posturas existenciales de los personajes, especialmente la de Paulino Cuartero.

En primer lugar, la evolución de Cuartero está dirigida a encontrar una solución a su profundo sentimiento de soledad existencial. Soldevila afirma que los personajes de la narrativa de Aub son «víctimas preferidas de la soledad,

29. Barrero, ob. cit., p. 238. 
hundidas en la sensación de vivir incomunicados, de hacer signos en un desolado mar de hielo» ${ }^{30}$. El primer capítulo de esta tercera parte comienza «in medias res» con una conversación entre Cuartero y un amigo. Cuartero le explica la soledad que le aqueja: «Me duele sentirme solo, teniendo la seguridad de que podría no estarlo. Me duele no tener más amigos que tú y Templado» ${ }^{31}$. Éste es el gran problema que se plantea Cuartero y que tratará de solucionar a partir de la revisión de sus principios cristianos.

La soledad, uno de los grandes ejes temáticos del existencialismo, nace del radical divorcio entre la conciencia y el mundo. El sujeto se ve atrapado en un círculo vicioso del que no puede escapar y que le aísla del «otro", dado que la soledad no le conecta con nada que no sea ella misma. La angustia que produce en el sujeto el vértigo del vacío le llevará a una continua, e imposible, búsqueda de protección en el otro. En opinión de Barrero, la soledad es también uno de los temas recurrentes de la novela existencial española ${ }^{32}$. Este sentimiento se convierte en el espacio conceptual en el que el protagonista de la novela existencial busca su "yo» más auténtico que, paradójicamente, es parcial y contingente. Se establece así una dialéctica entre la búsqueda de esa autenticidad, que enfrenta al sujeto a su libertad de elección para crearse, y la angustia que provoca la fractura con el otro y con el mundo.

A través de diferentes vivencias y reflexiones, Cuartero intenta buscar una verdad moral que le rescate de la soledad y le acerque a los otros, sin renunciar a su «yo» auténtico. A partir de sus fuertes convicciones católicas, pondrá todas sus esperanzas en encontrarse con un Dios comprensivo y humano que acabe con su angustia sin disolverle como sujeto. Buscará acceder a él a través de cuatro vías de experiencia y reflexión: el amor, la creación, la fe y el dolor. Como a través de cuatro filtros de la conciencia, Cuartero va pasando por cada uno de ellos hasta hallar a Dios y ser capaz de reformular su sentimiento de soledad.

Su periplo interior comenzará con el amor. Le había prometido a un amigo visitar a una muchacha para darle la noticia de la muerte de su padre, ocurrida durante la evacuación de Teruel. Cuartero miente a la muchacha, para no causarle una gran impresión y le explica que su padre está gravemente herido. Rosario entiende perfectamente que lo que Cuartero viene a anunciarle es la muerte de su padre. Durante todo este episodio Paulino Cuartero se ha ido sintiendo cada vez más atraído por ella, cuyas lágrimas cierran el capítulo.

Entre ambos comienza una relación amorosa, por supuesto a espaldas de la mujer de Cuartero que, sin embargo, adivina la aventura de su marido desde el principio. Barrero Pérez afirma en su estudio que «amor y muerte son las dos circunstancias existenciales en el que el personaje se siente inclinado a meditar sobre sí mismo y su conflictiva relación con el mundo externo» ${ }^{33}$. Del mismo modo, para Cuartero este sentimiento amoroso tendrá un sentido trascendental.

30. Campo de sangre, ob. cit., p. 219.

31. Campo de sangre, ob. cit., p. 297.

32. Barrero, ob. cit., p. 160.

33. Barrero, ob. cit., p. 100. 
Acostado junto a Rosario, Cuartero vuelve a tener un sentimiento de plenitud vital y reflexiona sobre cómo el amor de Rosario ha recompuesto las tres sustancias de la existencia: el mundo, el yo y Dios. En primer lugar, el mundo vuelve a adquirir sentido para Cuartero. Todo le parece irreal y superfluo menos Rosario. El mundo parece estar contenido en ella. Cuartero le dice a Rosario en su diálogo imaginario: "Quiero el mundo que me das esta mañana. Quiero el mundo a través de ti ${ }^{34}$. En segundo lugar, Cuartero se reconoce como un sujeto fragmentado por la guerra que ha recuperado la unidad gracias al amor de Rosario:

Objeto de mi deseo, objeto de mi satisfacción, reconstrucción de mi unidad, conducto de mi yo que me vuelve a mí mismo, a deshacer y desvanecer lo que había huido de mí: el deseo. Me reencuentro, me reabsorbo de ti. Y de la misma manera que Prometeo robó el fuego, te robo yo a $\mathrm{ti}^{35}$.

Cuartero, un nuevo Prometeo, ha robado el fuego del amor que debe iluminar su vida. Gracias al amor ha recuperado su unidad como sujeto que había saltado en mil pedazos con la guerra. Pero llega más lejos en su divagación y también encuentra la clave de la existencia de Dios: «Me quiere, me quiere a mí, y no por costumbre y no por dinero, por nada, por nada, porque sí. Y aún hay idiotas que no creen en Dios» ${ }^{36}$. El amor desinteresado de Rosario sólo puede explicarse por la existencia, evidente en ese momento para Cuartero, de Dios. Ese amor se contrapone al egoísmo del que nacía su soledad.

Con esta concepción del amor que emana de la experiencia y la reflexión de Cuartero, el arte narrativo de Aub se distancia de la novela existencial. Si bien, como decíamos más arriba, Aub coincidía con ésta en la idea de plantear el amor como el lugar donde reflexionar en torno a la existencia humana, su visión de este sentimiento es muy diferente. En la novela existencial española las relaciones entre los dos sexos se revelan imposibles e «in-auténticas», y suelen naufragar en la incomunicación o la alienación del yo protagonista, hasta tal punto que en algunos casos pueden conducir al protagonista a la enajenación mental, ya que como afirma Barrero: «La pasión amorosa mina no ya la individualidad del personaje, sino su propia estabilidad psicológica ${ }^{37}$. En esta misma línea representa este tipo de novela el acto sexual, que se percibe como una experiencia equiparable a la muerte. El sexo en la novela existencial suele conceptualizarse como un proceso de desintegración del «yo».

Frente a estas divergencias, la visión del amor que se desprende de la relación entre Paulino Cuartero y Rosario se conecta con la visión que Miguel de Unamuno tenía de la soledad. Según Roberts, en la obra de Unamuno podemos encontrar tres motivos que refieren a este sentimiento: la huida, el refugio y la búsqueda del otro ${ }^{38}$. En esta dirección, Cuartero en su búsqueda para acabar

34. Campo de sangre, ob. cit., p. 320.

35. Campo de sangre, ob. cit., p. 325.

36. Campo de sangre, ob. cit., p. 323.

37. Barrero, ob. cit., p. 184.

38. Roberts, ob. cit., p. 118. 
con la soledad encuentra en Rosario, primero, un escape de las relaciones «inauténticas», como la que mantiene con su mujer, que le alienan como sujeto; segundo, un refugio que le protege de la angustia; y, tercero, un camino que le acerca al otro y a Dios.

En el monólogo interior de Cuartero aparecen otros dos aspectos de fuerte sabor unamuniano. En primer lugar, la reflexión sobre la muerte conduce paradójicamente a la conciencia de la vida. Y, en segundo lugar, la idea de que la angustia vital proviene de la insuficiencia del lenguaje. Ambas ideas enlazan con la creación, el segundo de los caminos que debe transitar en su búsqueda de una solución para la soledad. El 10 de marzo, cuando Teruel ya había caído en manos rebeldes y tres días después de que comenzase su ofensiva sobre Aragón, Cuartero vuelve a Barcelona proveniente de Perelada. A su llegada a casa discute con su mujer que ahora quiere trabajar como secretaria. Pilar echa en cara a su marido no ayudarle a conseguir el puesto que busca y, de nuevo, no preocuparse por su familia. En el calor de la discusión le hace saber que conoce su lío con Rosario. Paulino lo niega y ambos se van a la cama sin hablarse. Junto a su mujer dormida, Cuartero experimenta un sentimiento de profunda soledad tan opuesto a la plenitud que sentía junto a Rosario. En otro diálogo ficticio su voz se dirige a sus propios sentimientos: «No tengo a nadie sino a ti, soledad $»^{39}$. La desolación de Cuartero junto a su mujer no puede ser más absoluta. Sólo encuentra una válvula de escape para su soledad al calor de los personajes de su teatro:

Sólo mis personajes unidos a mí por el cordón de la vida, heridos, sangrantes de las heridas de las palabras, que los vacían, entallan y decentan, como si fueran piedras. ${ }^{40}$

Como Unamuno, Cuartero siente una relación trascendente con sus criaturas. Al igual que su autor está herido por la vida, sus personajes lo están de la insuficiencia de las palabras que no consiguen perfilarlos y sacarlos del bloque de piedra que los contiene. Sus personajes sólo son parásitos de su mente, pero son los únicos que pueden compartir su soledad por el íntimo vínculo que se establece entre ellos: «Personajes míos atados a mí por mil cordones umbilicales» ${ }^{41}$. Creador y criatura sufren de la misma angustia, pero el poder sentir la vida de sus personajes, permite a Cuartero tomar conciencia de la suya propia.

El tercer paso lo dará Cuartero a través del cuestionamiento de su fe. El 18 de marzo por la noche Cuartero dialoga con Fajardo con quien discute sobre la existencia de Dios. Para su amigo el ser humano «necesita de la soledad para inventar el Dios único» ${ }^{42}$. Cuartero encoleriza ante estas palabras. No puede creer la simplicidad del argumento de Fajardo. Sabe que la soledad conduce a todo lo contrario; conduce a la duda de la existencia de Dios y al abismo

39. Campo de sangre, ob. cit., p. 360.

40. Campo de sangre, ob. cit., p. 360.

41. Campo de sangre, ob. cit., p. 359.

42. Campo de sangre, ob. cit., p. 392. 
de la desesperación existencialista. El camino auténtico hacia la solución del problema existencial reside en el sujeto individual, no en la colectividad. En concreto, en la relación directa entre el sujeto y Dios en el seno de una religión «agonista» basada en la duda y la lucha.

Más adelante, durante la noche del 19 de marzo, Cuartero se encuentra en casa con sus hijos para los que no tiene respuestas sobre la guerra que está marcando su infancia. Se ensimisma de nuevo en sus propios pensamientos y se pregunta por la existencia de Dios. Sopesa así la esencia irracional de la fe: «La fe es ciega. [...] Todos los que hacen algo es porque les sale de adentro y creen en Dios» ${ }^{43}$. Toda acción está movida en última instancia por una creencia irracional en el ser humano y en el mundo. La fe, parece decirnos Cuartero, está en el origen de toda acción humana y, en última instancia, esto sólo puede conducir a Dios. Quienes no se cuestionan su propia fe sólo están preocupados de su salvación en esta vida. Sólo la duda angustiada puede conducir a Dios. Cuartero hace una afirmación que bien podría haber firmado el mismo Miguel de Unamuno:

No se puede creer en Dios sin haber dudado de él. Sin desesperar. Quien tiene plena seguridad de la existencia de Dios, no cree en Dios. Lo que los hombres piensan de las cosas es más importante que las cosas mismas ${ }^{44}$.

Con sus palabras finales establece la misma relación entre Dios y el hombre, que entre el hombre y sus criaturas artísticas. La idea de Dios es más importante que la existencia «de facto» de Dios, de la misma manera que los personajes de Cuartero son más importantes que su mismo autor; de hecho, las sustancias del creador y la criatura llegan a confundirse. La reflexividad del pensamiento de Cuartero tiene una herencia directa de la meta-ficción unamuniana. Recordemos que, por ejemplo, en Niebla ${ }^{45}$ lejos de ser un juego, la meta-ficción tiene un calado transcendente al explicitar la realidad/ficción tanto del personaje como del autor cuyos universos se confunden. En general, Cuartero es un agonista como lo es el Unamuno de Del sentimiento trágico de la vida ${ }^{46}$. Su búsqueda angustiada de Dios es la demostración paradójica de la existencia de Dios mismo. La búsqueda por lo tanto no tiene fin, porque Dios se encuentra en el territorio de la duda y la contradicción que asolan al sujeto. La soledad existencial de Cuartero no tiene una solución tranquilizadora.

Después de este episodio ya sólo le queda a Cuartero pasar por la experiencia del dolor. El 19 de marzo caen de nuevo las bombas sobre Barcelona, su hija está enferma y debe salir a la calle para ir a la farmacia donde tienen preparadas las medicinas para la pequeña. Vuelve completamente desencajado a su casa. En la calle ha visto en una ambulancia el cuerpo desmembrado de Rosario, amontonado junto a otros cadáveres. Una terrible sensación de culpabilidad le

43. Campo de sangre, ob. cit., p. 404.

44. Campo de sangre, ob. cit., p. 405.

45. Miguel de Unamuno, Niebla, Madrid, Renacimiento, 1928.

46. Miguel de Unamuno, Del sentimiento trágico de la vida, Madrid, Renacimiento, 1912. 
invade. Se encierra en el baño. No puede reconocer su rostro en el espejo. «¿Por qué hay una sola palabra para el dolor moral y el de la carne? ¡No me duele nada y me retuerzo de dolor! Me duele el alma. Me duele el alma. ¡Una palabra, una palabra para decir lo que siento!» ${ }^{47}$ se dice a sí mismo.

Del dolor existencial, afirma Roberts, emana un profundo sentimiento de culpa original:

Para el pensamiento existencialista la «autenticidad» del existente supone un verdadero proceso de apropiación de la culpa original del hombre, algo muy semejante a la conversión religiosa, que implica el arrepentimiento y el nacimiento del «hombre nuevo $»^{48}$.

La culpabilidad nace en Paulino ante la sospecha de que la muerte de Rosario tal vez sea el castigo que Dios le manda por el adulterio cometido. Cuartero sufre su conversión final y su renacimiento como ser humano al sentir ese dolor y esa culpa que le descubren al Dios de la religión "agonística». «Nunca se había sentido más cerca de Dios. La evidencia de su pecado le hacía sentirse miserable» ${ }^{49}$. De nuevo una paradoja, sólo el dolor de ser consciente de haber pecado evidencia la existencia de un Dios, al que ahora clama para que le indique un camino o para que le dé muerte y acabe con el dolor. Tras la desesperación de la angustia viene la calma de la resignación. Cuartero se arrepiente de su pecado y se aplicará la penitencia: "Yo mismo me castigaré volviendo al recto camino".

Cuatro han sido los caminos por los que Cuartero ha llegado a la evidencia de la existencia de Dios: el amor de Rosario a través de la cual se había reconciliado con las tres sustancias (mundo, hombre y Dios), la creación paradójica de personajes de teatro que confundían su sustancia con la de su creador, el principio irracional de la fe que mueve toda acción humana y, finalmente, el dolor por la pérdida de Rosario y la conciencia de culpa y pecado que le han acercado a Dios. Todos estos caminos confluyen en el capítulo final para dar solución a la soledad de Cuartero. Una solución tal vez con minúscula, pero la única solución posible dentro de un mundo imperfecto que se cae a pedazos. Cuartero se dirige en otro diálogo ficticio a su amante muerta: «Estoy solo, ¿te das cuenta? ¡Solo! Con Dios que me mira y me aplasta ${ }^{50}$.

\section{CAMPO DE SANGRE Y LA NOVELA EXISTENCIAL ESPAÑOLA}

A lo largo del análisis de Campo de sangre hemos observando tanto convergencias como divergencias en el modo construcción del personaje aubiano con el de la novela existencialista. Toda la novela espańola de la época, tanto la del interior como la del exilio, así como la novela europea nacen de

47. Campo de sangre, ob. cit., p. 415.

48. Roberts, ob. cit., p. 111.

49. Campo de sangre, ob. cit., p. 415

50. Campo de sangre, ob. cit., p. 418. 
un contexto histórico-social común. La postguerra planteó a los intelectuales europeos unos mismos interrogantes sobre la condición humana. Esta coincidencia en el contexto de enunciación produjo importantes similitudes tanto en el contenido como en la forma de la novela de postguerra. En este ambiente ignorar el problema era ya una postura en sí misma. De esta manera Max Aub, sin ser en ningún caso un autor existencialista, reflexionó en sus obras sobre diferentes aspectos del problema de la existencia.

Roberts enumera en su trabajo las características generales de la novela existencial espańola: primero, la índole individual del protagonista; segundo, el estado de incertidumbre y angustia; tercero, la rememoración frecuente del pasado; cuarto, el análisis de la conciencia y la autocrítica constante, y, quinto, el sentimiento de soledad y desarraigo ${ }^{51}$. El análisis contrastivo de Campo de sangre a partir de estas características arroja en principio más similitudes que diferencias, pero también anuncia la dirección de la principal divergencia. En primer lugar, la estética "simultaneísta» aprendida por Aub en el unanimismo francés entra en pugna con la búsqueda del propio "yo» de los personajes principales, especialmente Paulino Cuartero. En términos generales Campo de sangre tiene uno de sus principales puntos de fractura en la tensión que se establece entre ambos modelos textuales. Este personaje pugna por individualizarse y encontrar su «yo» auténtico frente al calidoscopio de personajes habitual de la novela aubiana.

En segundo lugar, la Guerra Civil crea ese estado de incertidumbre que determina la conducta de todos los personajes y que les obliga a tomar una postura moral ante el absurdo de la realidad. En el caso de Paulino Cuartero la necesidad de encontrar un Dios auténtico choca con la duda interior e íntima. Este conflicto escenifica la disociación de la conciencia y el mundo produciendo la angustia existencial.

En tercer lugar, la principal diferencia entre la novela existencial española y Campo de sangre se refiere a la «rememoración del pasado». En la novela existencial los personajes rememoran las experiencias traumáticas pasadas para conectarlas con su comportamiento presente. En Campo de sangre no existe esa rememoración por el simple motivo de que la situación límite se encuentra en el presente histórico del personaje. La temporalidad vital de Cuartero se ubica en la guerra que está viviendo. No necesita rememorar el pasado, el episodio traumático todavía está ante oculos.

En cuarto lugar, Cuartero lleva a cabo un continuo auto-análisis y auto-crítica de su conciencia, en su búsqueda de una postura moral más auténtica ante el horror cotidiano. Cuartero se para a analizar el efecto que produce en su interior su experiencia del amor, la creación, la fe y el dolor, que le conducen a Dios.

Finalmente, la soledad y el desarraigo son los dos conflictos presentes en todos los personajes de Campo de sangre. Cuartero es el personaje que los explicita más abiertamente, al plantear su problemática existencial a partir de su profundo sentimiento de soledad.

51. Roberts, ob. cit., pp. 264-5. 
El análisis de estas coincidencias también señala el diferente tratamiento de la relación del sujeto con el mundo. Esta divergencia surge de nuevo cuando analizamos otro punto de coincidencia entre la novela existencial espańola y Campo de sangre, y que reside en el retorno al realismo. El primero en señalar este aspecto fue Gonzalo Sobejano es su estudio Novela española de nuestro tiempo. En este ensayo Sobejano prefiere hablar de «realismo existencial», en lugar de hablar de novela existencial como lo hacen Roberts y Barrero ${ }^{52}$. Esta vuelta al realismo es la principal característica que la diferencia de la novela existencial europea, más interesada por la concreción de una filosofía a priori y la especulación abstracta. Max Aub, por su parte, en su ensayo Discurso de la novela española contemporánea ${ }^{3}$ publicado en 1945, había denunciado la perniciosa experiencia que en su opinión había supuesto la novela de la vanguardia y afirmaba que el único camino viable para la novela española era la vuelta al realismo.

En este sentido Campo de sangre está plenamente emparentado con la novela existencial española. Tanto para Aub como para los autores existenciales españoles la fábula novelesca, la concreción de los personajes y la circunstancia histórica tienen un peso mayor que la especulación meditativa y la plasmación de ideas filosóficas. En general, frente al modelo novelístico a priori del existencialismo europeo, la novelística española, y con ella Max Aub, apostaron por un tipo de novela a posteriori en la que el conflicto existencial nacía de una realidad histórica concreta.

La principal diferencia entre Campo de sangre y la novela existencial española es precisamente el grado de realismo. La novela de Aub es si cabe más realista que las novelas existenciales españolas. Este realismo de Aub se puede analizar a partir de tres características: la subjetividad, la temporalidad y el modelo textual. En primer lugar, en la novela existencial española el aspecto existencial está subsumido en lo psicológico ${ }^{54}$. Sus personajes son sujetos alienados del mundo que les circunda. Este subjetivismo, sin llegar al extremo de la novela europea, lleva al héroe a una visión distorsionada de la realidad.

En el caso de Campo de sangre existe una pugna entre el análisis de la conciencia de sus personajes, en especial de Paulino Cuartero, y el deseo de representar la sociedad del periodo de la guerra. En la novela existencial se produce un movimiento dialéctico dentro de la psicología del mismo personaje. Barrero nos recuerda como dentro del héroe existencial coexisten de manera paradójica dos fuerzas en continua pugna: el desprecio por la especie humana y el orgullo autoafirmador de pertenecer a ella ${ }^{55}$. El movimiento dialéctico, por tanto, sobre el que se basa la novela existencial busca conciliar ambos extremos dentro del sujeto. En este sentido este modelo de novela es profundamente subjetivo, en

52. Gonzalo Sobejano, Novela española de nuestro tiempo (en busca del pueblo perdido), Madrid, Prensa española, 1970, pp. 35-6.

53. Max Aub, Discurso de la novela española contemporánea, México D.F., Colegio de México, 1945.

54. Barrero, ob. cit,. p. 56.

55. Barrero, ob. cit., p. 81. 
cuanto que el mundo queda completamente desconectado del sujeto. Campo de sangre, por el contrario, se construye sobre un movimiento dialéctico muy diferente, el que se produce entre el sujeto y el mundo. La realidad inmediata es la que plantea a Cuartero la necesidad de reflexionar sobre su propio «yo», la que le demanda que tome una postura moral ante los acontecimientos que experimenta y la que origina en él sentimientos como la angustia, la soledad, el dolor o la decepción. El elemento existencial predominante en Campo de sangre reside en la necesidad de buscar una solución a la disociación de la relación del sujeto con el mundo, fuente de esos sentimientos. Mientras la novela existencial renuncia a esta búsqueda e intenta salvar al sujeto de la fragmentación o la disolución, Aub ensaya diferentes soluciones que den una salida a su fe en el ser humano inserto en su sociedad. Esta búsqueda cristaliza en un realismo mucho más objetivo que el de la novela existencial por cuanto que no se olvida de ninguna de las dos sustancias esenciales: el mundo y el sujeto.

En esta misma línea se establece la diferente temporalidad de Campo de sangre y la novela existencial. Según Barrero, la novela existencialista, sin llegar al extremo de su homóloga europea, tendió reiteradamente a la intemporalidad ${ }^{56}$. Por el contrario, en todo el ciclo de El laberinto mágico el elemento histórico es uno de los elementos fundamentales. A lo largo del análisis del personaje existencial de Campo de sangre hemos podido entrever la relación del destino del héroe existencial con el de la sociedad. Según afirma Lukács en La novela histórica $^{57}$, la relación dialéctica entre personaje y sociedad es la base de este género novelístico. La fidelidad a la temporalidad histórica y la redacción de Campo de sangre sobre el modelo de novela histórica objetivan el contenido de la novela, alejándola del subjetivismo existencial.

Finalmente, al modelo histórico de Campo de sangre se une el de la «novela simultaneísta», influencia del unanimismo francés de Jules Romains. Campo de sangre, pese a la necesidad de individualización del personaje de Paulino Cuartero, también es una novela de personaje colectivo. Como es habitual en las novelas de Aub, el destino de la colectividad es una de las preocupaciones fundamentales. Junto a Cuartero desfila toda una constelación de personajes más o menos perfilados que busca representar la sociedad como un todo orgánico. Cabe achacarle a Aub que tanto en Campo de sangre, como en el resto de novelas del ciclo, no fue capaz de ligar todos estos modelos textuales, lo cual hubiera concluido en un modelo con una nueva visión unitaria del mundo, una visión imposible si tenemos en cuenta la cercanía temporal de la experiencia traumática de la guerra. Campo de sangre es una novela interesante precisamente por las fracturas que presenta entre la subjetividad de sus elementos existencialistas, la objetividad del simuntaneísmo unanimista y la temporalidad historicista que afecta a ambas.

56. Barrero, ob. cit., p. 257.

57. Georg Lukács, La novela histórica, México, D.F., Era, 1966. 


\section{Conclusiones}

Aub, como todos los autores del momento, se sintió en la necesidad de dar respuesta a los interrogantes que la postguerra planteaba. Como señalaba en sus Diarios, entre la novela existencial y su obra hay una clara coincidencia ideológica, en cuanto que ambas plantean el problema de la existencia humana, la angustia y el desarraigo, y la necesidad de adoptar una postura moral coherente con la autenticidad del sujeto. Sin embargo, el punto de vista de Aub es mucho más complejo que el de la novela existencial. Coincido con Soldevila cuando afirma que:

Creemos que el fundamento temático -como sus reflejos estructurales- de las novelas de Aub es básicamente la cuestión de la intromisión de la vida del individuo y de la sociedad, junto con el de la interpenetración de estos dos polos del mundo ${ }^{58}$.

Frente al divorcio absoluto entre el sujeto y el mundo, que ha provocado esa intromisión de la vida, y la subjetividad extrema de la novela existencial, Campo de sangre, y con ella todo El laberinto mágico, descansa sobre la base de la búsqueda de un punto de conciliación dialéctico entre sujeto y mundo, y por lo tanto una postura más objetiva que la propuesta por la novela existencial. Aub siempre criticó el subjetivismo de la novela existencialista por el componente irracional que acarrea consigo. El 16 de enero de 1952, al hilo de la publicación del libro Problemática de la literatura de Guillermo de Torre ${ }^{59}$, Max Aub apuntaba en sus diarios:

Me doy cuenta, a mis cuarenta y ocho años, de lo poco que ha significado siempre para mí esa enorme ola irracionalista que sumergió el mundo durante casi toda mi vida. Nunca dudé de la razón, siempre tuve al instinto y a la sinrazón como meros sustentos inferiores, de los que salió la claridad, y a sus adoradores como escritores menores, interesantes sin duda, pero de segundo orden. Y me reafirmo en mí mismo, aun a pesar de pasar ante los ojos de los conocedores -¿quiénes?- como un liberalote del siglo pasado ${ }^{60}$.

Aub siempre se mantuvo fiel a los ideales propios del siglo XIX que nacieron con la Revolución: libertad, igualdad y fraternidad, herederos del racionalismo ilustrado. Esta fe racionalista hizo que a Aub le repugnara cualquier ideario nacido tanto del vitalismo irracionalista como del subjetivismo existencialista. No es extraño que usara formas novelescas nacidas de propuestas estéticas del siglo XIX como la novela histórica o la novela «simultaneísta», y huyese de la autobiografía confesional de la novela existencial.

Por otra parte, el régimen fascista triunfante en España impidió cualquier tipo de agencia crítica del sujeto sobre el conjunto social. La novela existencial,

58. Soldevila Durante, ob. cit., p. 230.

59. Guillermo de Torre, Problemática de la literatura, Buenos Aires, Losada, 1966.

60. M. Aub, Diarios I, ob. cit., p. 211. 
producto de este momento histórico, encerró al sujeto en sí mismo y procuró dar expresión a la propia dialéctica interna sobre el conflicto de su identidad como tal sujeto. Sin embargo, el exilio mantuvo un principio utópico en su visión del sujeto y del mundo del que la novela del interior careció. Para los escritores del exilio el reloj de la historia se paró en 1939 y todo su esfuerzo intelectual estuvo centrado en restablecer el proyecto ideológico republicano ${ }^{61}$. En general, el exilio intelectual español nunca se insertó de manera definitiva en el campo cultural del país de acogida, sino que siempre consideró pasajera su situación y comenzó desde el primer día a planear la nueva España que se construiría tras el regreso. Aub siempre fue fiel a este ideario sustentado sobre un principio utópico en el que el sujeto volvería a tener el control del mundo, es decir, a la idea de una relación dialéctica entre el sujeto y el mundo. En Una carta Aub afirmaba la imposibilidad del sujeto de aislarse del mundo como, en su opinión, proponía la novela existencial ${ }^{62}$.

Edward Said señala en su ensayo Reflections on exile ${ }^{63}$ como el exilio resulta también ser una liberación. Esa liberación fue la que permitió al exilio mantener la utopía frente al pesimismo radical de los escritores que quedaron en el interior de una España regida por el discurso único del Franquismo. Frente al pesimismo existencial de los escritores del interior sobre el ser humano y el mundo, Aub afirmaba, en una fecha tan cercana todavía al final de la Guerra Civil como era el año 1949, su fe en el progreso, en el arte y la amistad ${ }^{64}$; en definitiva, su fe en el ser humano.

61. Sobre este aspecto trata pormenorizadamente Sebastiaan Faber en su libro Exile and Cultural Hegemony, ob. cit.

62. M. Aub, Una carta, ob. cit., p. 56.

63. Edward Said, Reflections on Exile and other Essays, Cambridge, Mass., Harvard University Press, 2000.

64. M. Aub, Carta, ob. cit., p. 60. 